\title{
The effects of cardiac output and pulmonary arterial hypertension on volumetric capnography derived-variables during normoxia and hypoxia
}

Mosing, Martina ; Kutter, Annette P N ; Iff, Samuel ; Raszplewicz, Joanna ; Mauch, Jacqueline ; Bohm, Stephan H ; Tusman, Gerardo

\begin{abstract}
The aim of this study was to test the effect of cardiac output (CO) and pulmonary artery hypertension (PHT) on volumetric capnography (VCap) derived-variables. Nine pigs were mechanically ventilated using fixed ventilatory settings. Two steps of PHT were induced by IV infusion of a thromboxane analogue: PHT25 [mean pulmonary arterial pressure (MPAP) of $25 \mathrm{mmHg}$ ] and PHT40 (MPAP of $40 \mathrm{mmHg}$ ). CO was increased by $50 \%$ from baseline (COup) with an infusion of dobutamine $\geq 5 \mu \mathrm{g} \mathrm{kg}-1 \mathrm{~min}-1$ and decreased by $40 \%$ from baseline (COdown) infusing sodium nitroglycerine $\geq 30 \mu \mathrm{g} \mathrm{kg}-1 \mathrm{~min}-1$ plus esmolol $500 \mu \mathrm{g} \mathrm{kg}-1 \mathrm{~min}-1$. Another state of PHT and COdown was induced by severe hypoxemia (FiO2 0.07). Invasive hemodynamic data and VCap were recorded and compared before and after each step using a mixed random effects model. Compared to baseline, the normalized slope of phase III (SnIII) increased by $32 \%$ in PHT25 and by $22 \%$ in PHT40. SnIII decreased non-significantly by $4 \%$ with COdown. A combination of PHT and COdown associated with severe hypoxemia increased SnIII by $28 \%$ compared to baseline. The elimination of $\mathrm{CO} 2$ per breath decreased by $7 \%$ in PHT 40 and by $12 \%$ in COdown but increased only slightly with COup. Dead space variables did not change significantly along the protocol. At constant ventilation and body metabolism, pulmonary artery hypertension and decreases in CO had the biggest effects on the SnIII of the volumetric capnogram and on the elimination of CO2.
\end{abstract}

DOI: https://doi.org/10.1007/s10877-014-9588-0

Posted at the Zurich Open Repository and Archive, University of Zurich

ZORA URL: https://doi.org/10.5167/uzh-101353

Journal Article

Published Version

Originally published at:

Mosing, Martina; Kutter, Annette P N; Iff, Samuel; Raszplewicz, Joanna; Mauch, Jacqueline; Bohm, Stephan $\mathrm{H}$; Tusman, Gerardo (2015). The effects of cardiac output and pulmonary arterial hypertension on volumetric capnography derived-variables during normoxia and hypoxia. Journal of Clinical Monitoring and Computing, 29(1):187-196.

DOI: https://doi.org/10.1007/s10877-014-9588-0 


\title{
The effects of cardiac output and pulmonary arterial hypertension on volumetric capnography derived-variables during normoxia and hypoxia
}

\author{
Martina Mosing • Annette P. N. Kutter • \\ Samuel Iff · Joanna Raszplewicz $\cdot$ Jacqueline Mauch • \\ Stephan H. Bohm • Gerardo Tusman
}

Received: 4 March 2014/ Accepted: 31 May 2014/Published online: 8 June 2014

(C) Springer Science+Business Media New York 2014

\begin{abstract}
The aim of this study was to test the effect of cardiac output $(\mathrm{CO})$ and pulmonary artery hypertension (PHT) on volumetric capnography (VCap) derived-variables. Nine pigs were mechanically ventilated using fixed ventilatory settings. Two steps of PHT were induced by IV infusion of a thromboxane analogue: $\mathrm{PHT}_{25}$ [mean pulmonary arterial pressure (MPAP) of $25 \mathrm{mmHg}$ ] and $\mathrm{PHT}_{40}$ (MPAP of $40 \mathrm{mmHg}$ ). CO was increased by $50 \%$ from baseline $\left(\mathrm{CO}_{\text {up }}\right)$ with an infusion of dobutamine $\geq 5 \mu \mathrm{g}$ $\mathrm{kg}^{-1} \min ^{-1}$ and decreased by $40 \%$ from baseline $\left(\mathrm{CO}_{\text {down }}\right)$ infusing sodium nitroglycerine $\geq 30 \mu \mathrm{g} \mathrm{kg}^{-1} \mathrm{~min}^{-1}$ plus esmolol $500 \mu \mathrm{g} \mathrm{kg}^{-1} \mathrm{~min}^{-1}$. Another state of PHT and $\mathrm{CO}_{\text {down }}$ was induced by severe hypoxemia $\left(\mathrm{FiO}_{2} 0.07\right)$. Invasive hemodynamic data and VCap were recorded and compared before and after each step using a mixed random effects model. Compared to baseline, the normalized slope of phase III $\left(\mathrm{Sn}_{\text {III }}\right)$ increased by $32 \%$ in $\mathrm{PHT}_{25}$ and by $22 \%$ in
\end{abstract}

M. Mosing ( $\square)$ · A. P. N. Kutter · J. Raszplewicz

Division of Anaesthesiology, Equine Department, Vetsuisse

Faculty, University of Zurich, Winterthurerstrasse 260,

8057 Zurich, Switzerland

e-mail: mmosing@vetclinics.uzh.ch

S. Iff

CTU Bern, University of Bern, Finkenhubelweg 11, 3012 Bern, Switzerland

\section{J. Mauch}

Department of Anesthesiology, Kantonsspital Luzern,

Spitalstrasse, 6000 Lucerne, Switzerland

S. H. Bohm

Swisstom AG, Schulstrasse 1, 7302 Landquart, Switzerland

G. Tusman

Department of Anesthesiology, Hospital Privado de Comunidad, Mar del Plata, Argentina
$\mathrm{PHT}_{40} \cdot \mathrm{Sn}_{\mathrm{III}}$ decreased non-significantly by $4 \%$ with $\mathrm{CO}_{\text {down }}$. A combination of PHT and $\mathrm{CO}_{\text {down }}$ associated with severe hypoxemia increased $\mathrm{Sn}_{\text {III }}$ by $28 \%$ compared to baseline. The elimination of $\mathrm{CO}_{2}$ per breath decreased by $7 \%$ in $\mathrm{PHT}_{40}$ and by $12 \%$ in $\mathrm{CO}_{\text {down }}$ but increased only slightly with $\mathrm{CO}_{\text {up }}$. Dead space variables did not change significantly along the protocol. At constant ventilation and body metabolism, pulmonary artery hypertension and decreases in $\mathrm{CO}$ had the biggest effects on the $\mathrm{Sn}_{\mathrm{III}}$ of the volumetric capnogram and on the elimination of $\mathrm{CO}_{2}$.

Keywords Cardiovascular changes - Pig - Pulmonary hypertension · Slope of phase III · Volumetric capnography

\section{Introduction}

Volumetric capnography (VCap-Fig. 1), the expired $\mathrm{CO}_{2}$ in one tidal breath, is an attractive tool for monitoring mechanically ventilated patients [1-3]. Such monitoring is based on the particular kinetics of $\mathrm{CO}_{2}$, which provides clinically relevant information not only about ventilation [4-6] but also about body metabolism and lung perfusion [7-10].

Most of the experimental and clinical studies regarding VCap have been dedicated to its function as a respiratory monitoring tool [4-6, 11-13]. In these studies, body metabolism and hemodynamics were kept stable while ventilatory parameters were modified to see their effects on VCap. While these protocols ignored the effect of metabolism and hemodynamics on $\mathrm{CO}_{2}$ kinetics they revealed that an increase in the slope of phase III $\left(S_{\text {III }}\right)$ of VCap is indicative of an in-homogenous distribution of ventilation within lungs [11-17].

However, there is little information about the effects that altered hemodynamics have on VCap derived-variables. 

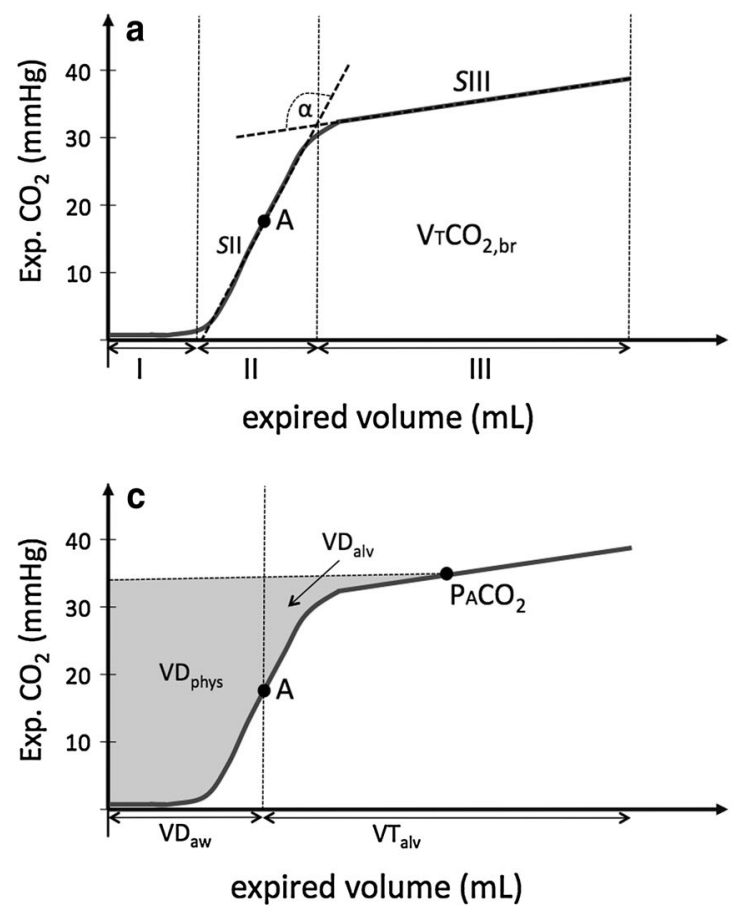

Fig. 1 Volumetric capnography (VCap) derived-variables. VCap is the volume of $\mathrm{CO}_{2}$ expired in one tidal breath. a VCap is divided into 3 phases (I-II-III) with 2 slopes that belongs to phases II and III. The angle alpha is the angle between the intersecting lines that follow such slopes. The amount of $\mathrm{CO}_{2}$ eliminated $\left(\mathrm{VTCO}_{2, \text { br }}\right)$ is represented by the area under the curve. b Tension-based values on the VCap curve: $\mathrm{PACO}_{2}$ is the $\mathrm{CO}_{2}$ value at the midpoint between the inflection point "A" and the end-tidal $\mathrm{CO}_{2}\left(\mathrm{PETCO}_{2}\right)$. The mixed expired $\mathrm{CO}_{2}$

This information should also be of clinical interest, as it will help clinicians understand and interpret the changes in VCap curves they see in clinical patients. Therefore, we hypothesized that hemodynamic parameters, mainly cardiac output (CO) and pulmonary artery pressure, would alter VCap derived-variables because pulmonary blood flow is a key determinant of $\mathrm{CO}_{2}$ kinetics.

Keeping ventilation and metabolism constant the objective of this experimental study was to analyze the modifications in VCap derived-variables which resulted from different hemodynamic interventions affecting pulmonary perfusion during normoxia and hypoxia.

\section{Materials and methods}

Nine healthy landrace pigs aged $62 \pm 1$ days, weighing $25.7 \pm 1.9 \mathrm{~kg}$ were studied.

\subsection{Anaesthesia and monitoring}

Pigs were premedicated with midazolam $1 \mathrm{mg} \mathrm{kg}^{-1}$ (Dormicum, Roche Pharma, Switzerland) and ketamine $15 \mathrm{mg} \mathrm{kg}^{-1}$ (Narketan, Vetoquinol, Switzerland) intramuscularly.

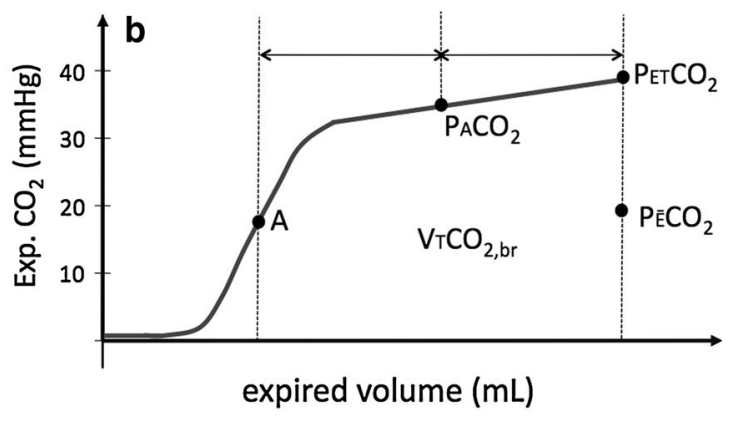

$\left(\mathrm{PECO}_{2}\right)$ represents the mean $\mathrm{CO}_{2}$ in the expired gas and is calculated multiplying $\mathrm{FECO}_{2}$ by barometric minus water vapour pressure. c The grey area is the graphical and theoretical illustration of Bohr's dead space, which is formed by the airway dead space $\left(\mathrm{VD}_{\mathrm{aw}}\right)$ and the alveolar dead space $\left(\mathrm{VD}_{\text {alv }}\right)$ determined by Bohr's dead space minus $\mathrm{VD}_{\mathrm{aw}}$. "A" is the inflection point of VCap that separates the airways from the alveolar compartments. For more details see text

Anaesthesia was induced with propofol (Propofol, Fresenius Kabi, Switzerland) and maintained with midazolam $0.5 \mathrm{mg} \mathrm{kg}^{-1} \mathrm{~h}^{-1}$, propofol $4 \mathrm{mg} \mathrm{kg}^{-1} \mathrm{~h}^{-1}$, fentanyl $20 \mu \mathrm{g} \mathrm{kg}^{-1} \mathrm{~h}^{-1}$ (Sintenyl, Sintetica SA, Switzerland) and pancuronium $0.2 \mathrm{mg} \mathrm{kg}^{-1} \mathrm{~h}^{-1}$ (Pavulon, Essex Chemie AG, Switzerland). Ringer's lactate $3 \mathrm{ml} \mathrm{kg}^{-1} \mathrm{~h}^{-1}$ (Ringer Laktat, Fresenius Kabi, Switzerland) was infused during the experiment.

After endotracheal intubation volume controlled mechanical ventilation (S/5 Advance Anaesthesia Machine, DatexOhmeda Inc., Madison, WI, USA) was delivered with the following settings: tidal volume (VT) of $6 \mathrm{ml} \mathrm{kg}^{-1}$, positive end-expiratory pressure (PEEP) level of $7 \mathrm{~cm} \mathrm{H}_{2} \mathrm{O}$, inspiratory-to-expiratory ratio of $1: 1$ and $\mathrm{FiO}_{2} 0.5$. Later, only the respiratory rate (RR) was adjusted to keep end-tidal partial pressure of $\mathrm{CO}_{2}\left(\mathrm{PETCO}_{2}\right)$ within the range $40 \pm 3 \mathrm{mmHg}$.

Standard ECG, pulse oximetry and oesophageal temperature were recorded every $5 \mathrm{~min}$. Bispectral index (Bispectral Index Monitor, Model A-2000, Aspect Medical System, Inc., Newton, MA, USA) was used for monitoring and adjustment of the depth of anaesthesia. A 20G catheter was placed in the carotid artery for blood gas sampling and arterial pressure monitoring. A pulmonary artery catheter (PAC; HANDS-OFF ${ }^{\circledR}$ Thermodilution Catheter, Arrow 
Deutschland GmbH, Erding, Germany) was inserted via the right internal jugular vein using pressure guidance. The PAC was used to obtain mixed venous blood samples, to monitor pulmonary artery pressures and to measure $\mathrm{CO}$ by thermodilution. To induce pulmonary hypertension an additional catheter was placed in the right atrium via the right jugular vein for administration of a thromboxane analogue.

\subsection{Volumetric capnography (VCap)}

After tracheal intubation the sensors of the VCap device $\mathrm{NICO}_{2}$ (Respironics Inc., Wallingford, Connecticut, USA) were placed between the endotracheal tube and the Y-piece of the breathing circuit. The mainstream $\mathrm{CO}_{2}$ infrared sensor, with a response time for T10-90\% of $60 \mathrm{~ms}$ and accuracy of $\pm 2 \mathrm{mmHg}$, was zeroed before each experiment following the manufacturer's instructions. The accuracy of the differential pressure sensor used to measure flows of the breathing gases (range $2-180 \mathrm{~L}$ and accuracy $\pm 3 \%$ ) was verified before each experiment using a calibration syringe. Data from the capnograph was recorded on a laptop for 3 min at each baseline and measurement period using dedicated software Datacoll (Respironics, Wallingford, CT, USA). Raw $\mathrm{CO}_{2}$ and flow data were used to construct VCap as previously described using custom-built software based on a Functional Approximation by a Levenberg-Marquardt algorithm [18].

VCap and its derived-variables can be seen in Fig. 1. These variables were classified as follows [18]:

Variables related to the shape of VCap (Fig. 1a):

- The VCap curve is separated in 3 phases: phase $I$ is the portion of the tidal volume free of $\mathrm{CO}_{2}$ that comes from airway dead space, phase II constitutes the portion of the tidal volume where increasing amounts of $\mathrm{CO}_{2}$ are coming from lung units with different rates of ventilation and perfusion and phase III represents pure alveolar gas.

- The slope of phase II $\left(S_{\text {II }}\right)$ was determined as the value of the 1st derivative at the inflection point (point "A") of the whole curve.

- The $S_{\text {III }}$ was calculated using only data from the 3 rd derivative of the mathematical function until the end of VT. This portion of the capnogram was then separated into three-thirds and the middle third was divided into ten equidistant points and their slopes were calculated as their respective 1 st derivatives. The mean value of the 10 slope values constituted $S_{\text {III. }}$. This slope was then normalized $\left(\mathrm{Sn}_{\text {III }}\right)$ by the mixed expired $\mathrm{CO}_{2}$ fraction $\left(\mathrm{FECO}_{2}=\mathrm{VTCO}_{2, \mathrm{br}} / \mathrm{VT}\right)$ to enable a comparison of slopes from tidal volumes of different sizes.

- The angle alpha is the angle formed by the intersection of the lines that follow $S_{\text {II }}$ and $S_{\text {III }}$.
$\mathrm{CO}_{2}$ tension-based values and elimination of $\mathrm{CO}_{2}$ (Fig. 1b):

- The end-expiratory partial pressure of $\mathrm{CO}_{2}\left(\mathrm{PETCO}_{2}\right)$ is calculated as the last expiratory $\mathrm{CO}_{2}$ value immediately before the start of the next inspiration.

- $\mathrm{PACO}_{2}$ is the mean alveolar partial pressure of $\mathrm{CO}_{2}$, located on $S_{\text {III }}$ at the midpoint between the mathematical inflection point of VCap (point A) and $\mathrm{PETCO}_{2}$.

- $\mathrm{PECO}_{2}$ is the mixed expired partial pressure of $\mathrm{CO}_{2}$ calculated multiplying $\mathrm{FECO}_{2}$ by the difference between barometric and water vapour pressure.

- $\mathrm{VTCO}_{2, \text { br }}$ is the area under the curve of the capnograms that represents the amount of $\mathrm{CO}_{2}$ eliminated per breath. It is obtained by integrating the flow and $\mathrm{CO}_{2}$ signals over inspiration and expiration.

Dead space variables (Fig. 1c):

- The ratio of dead space to tidal volume was calculated in a non-invasive fashion using Bohr's original formula [19]:

$\mathrm{VD}_{\mathrm{Bohr}} / \mathrm{VT}$ or $\mathrm{VD} / \mathrm{VT}=\left(\mathrm{PACO}_{2}-\mathrm{PECO}_{2}\right) / \mathrm{PACO}_{2}$

- $\mathrm{VD}_{\text {phys }}$ is the physiological dead space obtained as:

$\mathrm{VD}_{\text {phys }}=\mathrm{VD}_{\mathrm{Bohr}} / \mathrm{VT} * \mathrm{VT}$

- $\mathrm{VD}_{\mathrm{aw}}$ is the airway dead space measured as the first exhaled volume before the inflection point $A$. $V D_{a w}$ was also indexed by VT $\left(\mathrm{VD}_{\mathrm{aw}} / \mathrm{VT}\right)$.

- The alveolar dead space $\left(\mathrm{VD}_{\text {alv }}\right)$ was calculated subtracting $\mathrm{VD}_{\mathrm{aw}}$ from $\mathrm{VD}_{\text {phys }}$. The alveolar dead space was then indexed by the alveolar portion of the $\mathrm{VT}\left(\mathrm{VD}_{\mathrm{alv}} / \mathrm{VT}_{\mathrm{alv}}\right)$.

Enghoff's index $\left(\mathrm{VD}_{\mathrm{B}-\mathrm{E}} / \mathrm{VT}\right)$ [20]:

- This global index of the inefficiency of gas exchange is derived replacing $\mathrm{PACO}_{2}$ by $\mathrm{PaCO}_{2}$ in Bohr's formula:

$\mathrm{VD}_{\mathrm{B}-\mathrm{E}} / \mathrm{VT}=\left(\mathrm{PaCO}_{2}-\mathrm{PECO}_{2}\right) / \mathrm{PaCO}_{2}$

Enghoff"s index does not measure "dead space" in Bohr's sense but includes also effects from venous admixture since $\mathrm{PaCO}_{2}$ is directly influenced by these factors [21].

\subsection{Study protocol}

The protocol was conceived to describe the effects of pulmonary artery blood flow and pressure on VCap derived-variables at fixed ventilation and metabolism. We induced two steps of pulmonary hypertension $\mathrm{PHT}_{25}$ (mean 
pulmonary pressure of $25 \mathrm{mmHg}$ ) and $\mathrm{PHT}_{40}$ (mean pulmonary pressure of $40 \mathrm{mmHg}$ ) by a controlled infusion of U46619, a thromboxane analogue, at a rate of $2 \mu \mathrm{g} / \mathrm{kg} / \mathrm{min}$ into the right atrium. Rates were adjusted in order to reach the target values of mean pulmonary pressures of 25 or $40 \mathrm{mmHg}$.

$\mathrm{CO}$ was increased by $50 \%$ from baseline $\left(\mathrm{CO}_{\mathrm{up}}\right)$ administering $30 \mathrm{ml} \mathrm{kg}^{-1}$ Ringers lactate and dobutamine (Dobutrex, Teva Pharma AG, Switzerland) at an initial dose of $5 \mu \mathrm{g} \mathrm{kg}^{-1} \mathrm{~min}^{-1}$. The dose of dobutamine was adapted in order to reach the desired $\mathrm{CO}$ value. $\mathrm{CO}$ was decreased by $40 \%$ from baseline $\left(\mathrm{CO}_{\text {down }}\right)$ infusing sodium nitroglycerine at $30 \mu \mathrm{g} \mathrm{kg}^{-1} \mathrm{~min}^{-1}$ (Perlinganit, UCB Pharma AG, Switzerland) and esmolol at $500 \mu \mathrm{g} \mathrm{kg}^{-1} \mathrm{~min}^{-1}$ (Esmolol OrPha Swiss GmbH, Switzerland) until $\mathrm{CO}$ reached $40 \%$ of the baseline value.

All of the above interventions were performed in random order. Randomisation was accomplished using opaque envelopes. Baseline data were obtained and recorded for $3 \mathrm{~min}$ before each protocol step. Recording periods of 3 min were started after having reached stable conditions at the predefined pressures, $\mathrm{CO}$ and $\mathrm{FiO}_{2}$ values for $5 \mathrm{~min}$. At least $30 \mathrm{~min}$ of relaxation were allowed between steps such that all measured cardiovascular data could fall within $5 \%$ of the baseline values before initiating the next step.

Subjecting the animals to severe hypoxaemia created an additional condition of PHT combined with $\mathrm{CO}_{\text {down }}$. Due to its known life threatening effects on hemodynamics, this step was performed at the end of each experimental series so as not to run the risk of losing the animal for the other measurements. Fresh gas flowing into the inspiratory limb of the circle system was switched from an air- $\mathrm{O}_{2}$ mixture to air in nitrogen to achieve a $\mathrm{FiO}_{2}$ of 0.07 .

At each measurement point mixed venous and arterial blood samples were taken and immediately analysed for blood gases and haemoglobin using a co-oximeter (GEM 4000, IL, Axon Lab, Switzerland). Shunt fraction (Qs/Qt) representing the volume of venous admixture was calculated retrospectively using Berggren's equation [22]:

$\mathrm{Qs} / \mathrm{Qt}=\left(\mathrm{Cc}^{\prime} \mathrm{O}_{2}-\mathrm{CaO}_{2}\right) /\left(\mathrm{Cc}^{\prime} \mathrm{O}_{2}-\mathrm{C} \overline{\mathrm{v}} \mathrm{O}_{2}\right)$

where $\mathrm{Cc}^{\prime} \mathrm{O}_{2}$ is the capillary, $\mathrm{CaO}_{2}$ the arterial and $\mathrm{Cv} \overline{\mathrm{v}} \mathrm{O}_{2}$ the mixed venous content of $\mathrm{O}_{2}$.

\subsection{Statistical analysis}

For pig characteristics, means and proportions of variables were calculated at each step. Haemodynamic variables included into statistical analysis were CO, MPAP, MAP, HR, CVP and venous admixture, respiratory variables affecting the shape of the VCap curve were Phase I/VT, Phase II/VT, Phase III/VT, SII, SnIII, angle $\alpha$ and PETCO $_{2}$ and respiratory dead space variables were $\mathrm{VD}_{\text {phys }} \mathrm{VD}_{\mathrm{aw}}$, $\mathrm{VD}_{\text {alv }}, \mathrm{VD}_{\mathrm{aw}} / \mathrm{VT}, \mathrm{VD}_{\mathrm{alv}} / \mathrm{VT}_{\mathrm{alv}}, \mathrm{VD}_{\mathrm{Bohr}} / \mathrm{VT}$ and $\mathrm{VD}_{\mathrm{B}-\mathrm{E}} / \mathrm{VT}$. Continuous variables from baseline to measurement were compared by parametric or non-parametric tests. Categorical variables from baseline to measurement were compared by $\chi^{2}$ test. Covariates were split into two groups; hemodynamic and respiratory as described above. A mixed random effects model using pig as the random effect coefficient was used to determine the relationship of the different outcomes and the covariates per step. A fixed effect coding for measurement (before and after) was included to represent the treatment effect. For this analysis, the respiratory variables collected per breath of the steady state were aggregated in means, as the values for cardiovascular variables were collected once per step. Univariate models were built for all explanatory variables. All explanatory variables that had an association with the outcome at $p<0.25$ in the unadjusted analyses were included in the multivariable-adjusted analyses. Using a step-wise backward elimination process, the least significant variables were then removed from the base model. Only variables with $p<0.05$ remained in the final model. Data analysis was performed with STATA ${ }^{\circledR}$ for Windows version 12.0 (StataCorp LP, College Station, Texas, USA). Data are presented as mean $\pm \mathrm{SD}$.

\section{Results}

Data for all the steps from nine pigs were collected. Animals showed minimal inter-individual differences in all variables causing a small standard deviation. This caused statistically significant but clinically irrelevant small changes in most values in all steps. Therefore we present here changes in percent which exceed $5 \%$.

\subsection{Steps of pulmonary hypertension}

Target pressures of both PHT steps were reached in all pigs $\left(24.9 \pm 1.0 \mathrm{mmHg}\right.$ for $\mathrm{PHT}_{25}$ and $40.4 \pm 1.67$ for $\mathrm{PHT}_{40}$ ). Pulmonary hypertension was associated with significant decreases in $\mathrm{CO}$ and venous admixture by 7 and $36 \%$ at $\mathrm{PHT}_{25}$ and by 19 and $19 \%$ at $\mathrm{PHT}_{40}$. The other hemodynamic variables did not show changes $>5 \%$ during pulmonary hypertension (Table 1).

Pulmonary hypertension increased $\mathrm{Sn}_{\mathrm{III}}$ by $32 \%$ in $\operatorname{PHT}_{25}(p<0.0001)$ and by $22 \%$ in $\operatorname{PHT}_{40}(p<0.0001)$ (Table 2). $\mathrm{VTCO}_{2, \text { br }}$ did not change at $\mathrm{PHT}_{25}$ but decreased by $7 \%$ at $\mathrm{PHT}_{40}(p<0.0001)$ (Table 2$)$. VCap's tensionbased values showed no changes with PHT (Table 2).

$\mathrm{VD}_{\text {Bohr }} / \mathrm{VT}$ increased by $5 \%$ only at $\mathrm{PHT}_{40}$. $\mathrm{VD}_{\mathrm{B}-\mathrm{E}} / \mathrm{VT}$ showed similar and parallel changes as did $\mathrm{VD}_{\mathrm{Bohr}} / \mathrm{VT}$ (Table 3). 


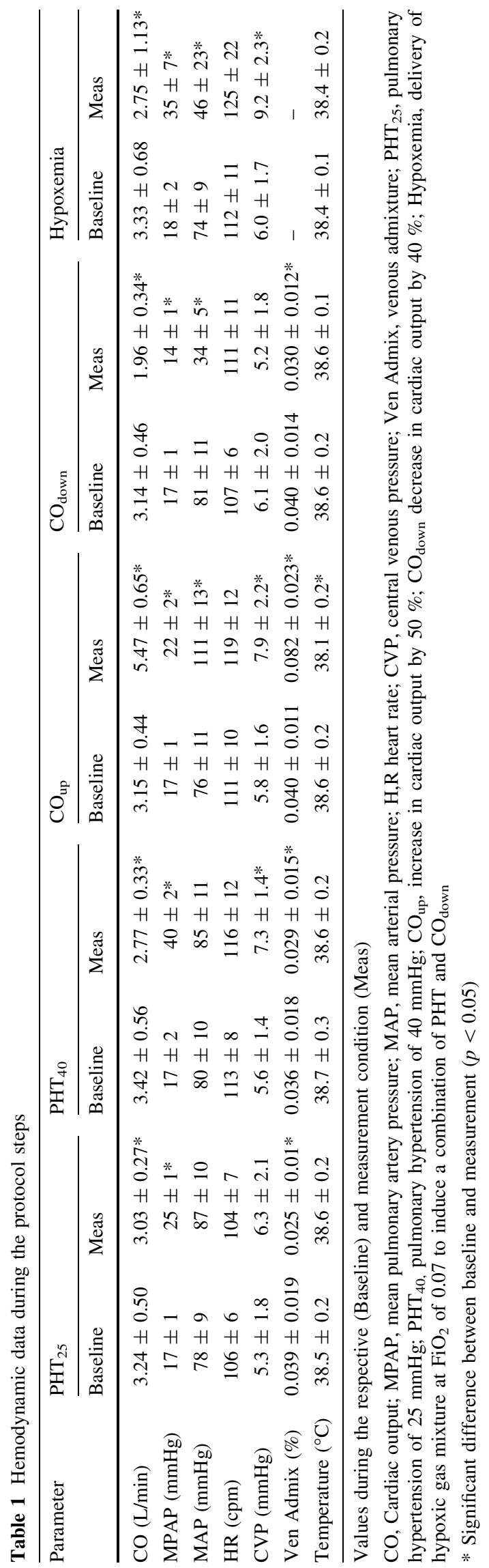

The mixed effects model suggested a significant influence of $\mathrm{CO}$ and venous admixture on all VCap variables at $\mathrm{PHT}_{40}$. At PHT 25 only $\mathrm{Sn}_{\text {III }}$ was significantly influenced by the hemodynamic variables.

\subsection{Step $\mathrm{CO}_{\text {up }}$}

The mean increase in $\mathrm{CO}$ from baseline in this step was $74 \%$ and was associated with an increment in MPAP (28\%), MAP (46\%), HR (7\%), and CVP (17\%). Venous admixture doubled from 4 to $8 \%$ (Table 1 ).

$\mathrm{CO}_{\text {up }}$ significantly increased $\mathrm{Sn}_{\text {III }}$ by $28 \%(p<0.0001)$ while $\mathrm{VTCO}_{2, \text { br }}$ did not change in this step $(p=0.249)$ (Table 2).

$\mathrm{VD}_{\text {Bohr }} / \mathrm{VT}$ and $\mathrm{VD}_{\mathrm{B}-\mathrm{E}} / \mathrm{VT}$ were unaltered $(<5 \%)$ (Table 3).

In the mixed effects model $\mathrm{CO}(p=0.026)$ showed significant effects on $\mathrm{Sn}_{\text {III }}$ (Figs. 2, 3).

\subsection{Step $\mathrm{CO}_{\text {down }}$}

CO decreased from baseline by $38 \%$ and was associated with decreases in MPAP by $18 \%$ and in MAP by $58 \%$ while the other hemodynamic variables remained unchanged. Venous admixture decreased only slightly from 4 to $3 \%$ (Table 1$)$.

$\mathrm{CO}_{\text {down }}$ decreased $S_{\text {II }}$ significantly by $10 \%(p<0.0001)$ while $\mathrm{Sn}_{\text {III }}(4 \%)$ was not affected. During $\mathrm{CO}_{\text {down }} \mathrm{VTCO}_{2, \mathrm{br}}$ decreased by $12 \%(p<0.0001)$ and VCap's tension-based values $\mathrm{PETCO}_{2}, \mathrm{PACO}_{2}$ and $\mathrm{PE} \mathrm{EO}_{2}$ decreased by 9,9 and $11 \%$, respectively (Table 2).

$\mathrm{VD}_{\text {Bohr }} / \mathrm{VT}$ and its components were not altered by $\mathrm{CO}_{\text {down }}$ while $\mathrm{VD}_{\mathrm{B}-\mathrm{E}} / \mathrm{VT}$ increased by $8 \%(p<0.0001)$ (Table 3$)$.

The mixed effects model revealed a significant influence of $\mathrm{CO}$ and MPAP on $\mathrm{VCO}_{2}$ while $S_{\mathrm{II}}$ and VCap's tensionbased values were mainly affected by $\mathrm{CO}$ and venous admixture.

\subsection{Hypoxaemia}

Breathing a hypoxic gas mixture decreased $\mathrm{CO}(18 \%)$ and MAP (38 \%) but increased MPAP (94\%), HR (12\%) and CVP $(50 \%)$ (all $p<0.0001)$ (Table 1). A significant effect of hypoxia on VCap derived-variables was observed only for $\mathrm{Sn}_{\text {III }}$, which showed an increase by $27 \%$ compared to baseline condition at high $\mathrm{FiO}_{2}$ (Table 2).

In the mixed effects model $\mathrm{CO}$ was the main cardiovascular variable affecting $S \mathrm{n}_{\text {III }}$.

\section{Discussion}

The results of this experimental study showed that changes in pulmonary blood flow and pressure affected mainly 


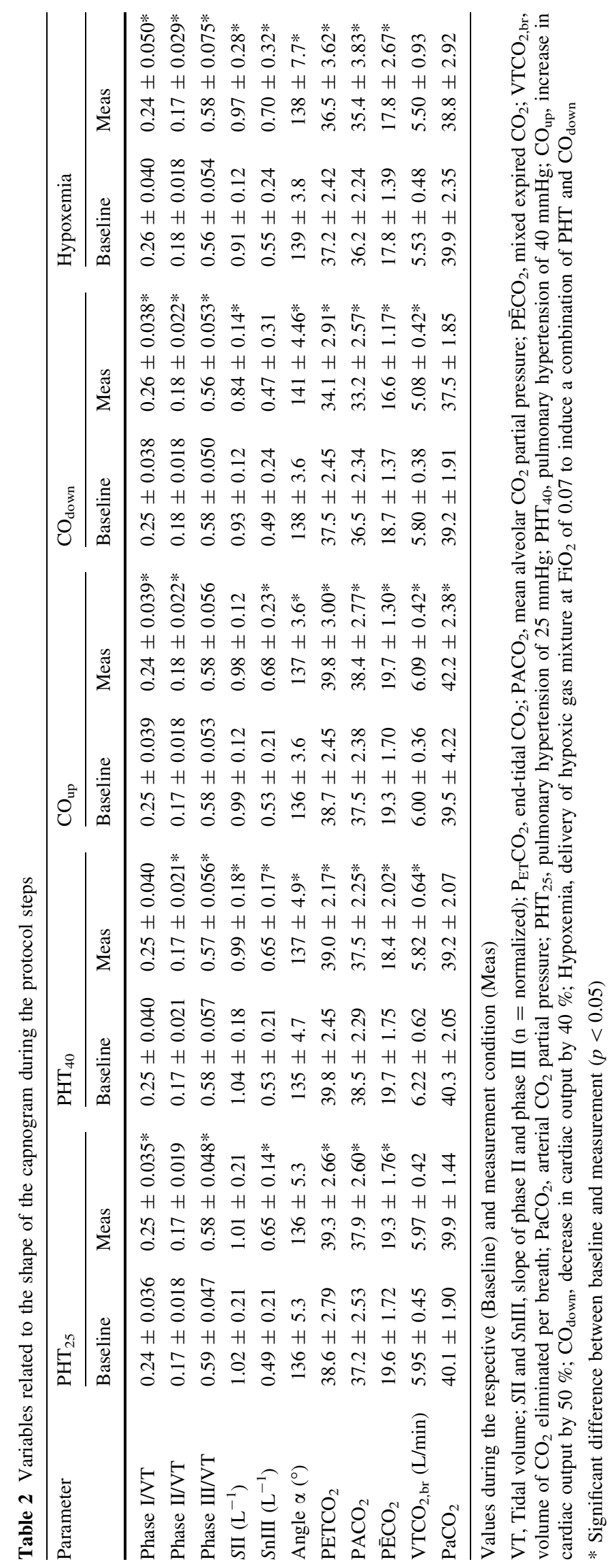




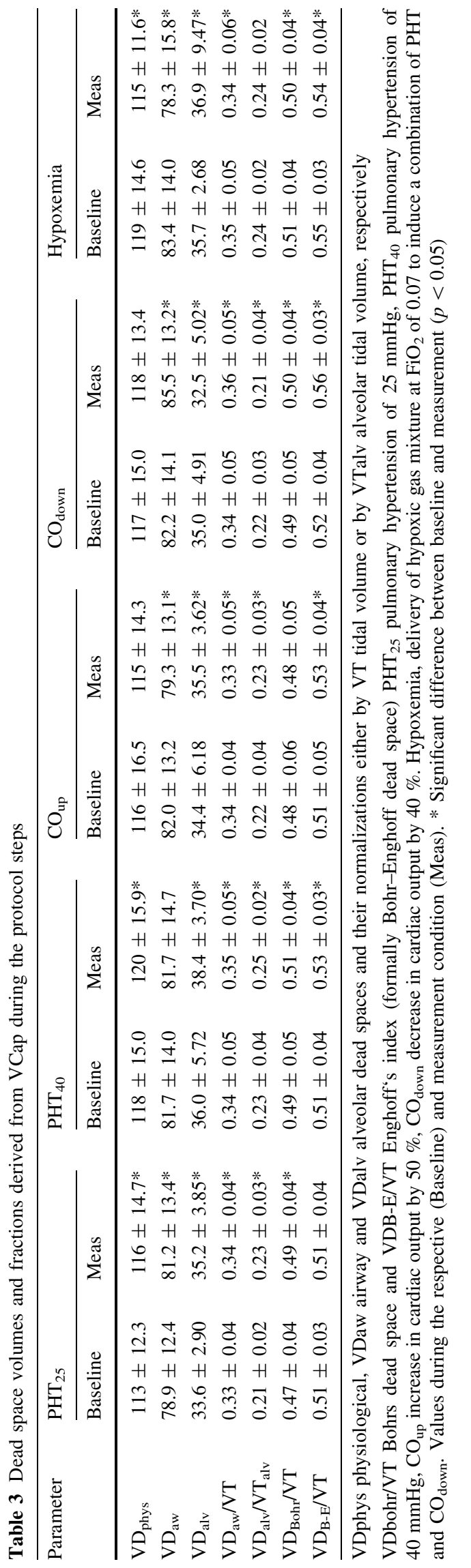

those variables of the capnogram that are related to its shape. The area under the curve and the $\mathrm{Sn}_{\mathrm{III}}$ were the ones affected the most while dead space was affected the least.

\subsection{The shape of the capnogram}

$S \mathrm{n}_{\text {III }}$ is the variable with the clearest link to the ratio of ventilation and perfusion (V/Q) [17, 23]. The positive sloping of $S \mathrm{n}_{\text {III }}$ is due to intra- and inter-regional inhomogenities in the distribution of pulmonary ventilation and its underlying mechanisms convection and diffusion [1416]. Thus, lung diseases such as atelectasis and bronchospam with a known inhomogeneous distribution of ventilation are associated with a steep while their effective treatments with a flat slope of $S n_{\text {III }}[11-13,24,25]$.

Pulmonary perfusion must alter $S \mathrm{n}_{\text {III }}$ simply because it is the other "key factor" in the V/Q equation influencing $\mathrm{CO}_{2}$ diffusion through the alveolar-capillary membrane. This also explains how $S n_{\text {III }}$ can be used as a qualitative surrogate for global matching of V/Q as has been suggested by several authors but only recently validated [17, 23].

Previous publications showed that $S \mathrm{n}_{\text {III }}$ decreases during states of low pulmonary blood flow such as in pulmonary embolism $[2,10,26,27]$. The same was seen in humans at the beginning of the weaning procedure from cardio-pulmonary by pass when pulmonary perfusion is very low [9]. These results can be explained by the fractal nature of the pulmonary circulation: any time pulmonary perfusion is distributed more peripherally within the lungs, the dichotomy of the vascular tree augments and blood flow becomes more heterogeneous, resulting in steeper $\mathrm{Sn}_{\text {III }}[9,28,29]$. The opposite effect is observed when the pulmonary perfusion is concentrated in certain parts of the lungs. Pulmonary perfusion remains within the central vascular tree when i.e. peripheral lung embolism or hypovolaemia prevent perfusion of the periphery or in the dependent parts of the lungs due to the gravitational orientation of lung perfusion at low CO states [2, 30, 31].

Our findings fit with the above explanations. On one hand, $\mathrm{Sn}_{\text {III }}$ increased with PHT, $\mathrm{CO}_{\text {up }}$ and hypoxemia causing a massive increase in MPAP because of a re-distribution of pulmonary perfusion towards the periphery caused by capillary recruitment [32,33]. On the other hand, $\mathrm{Sn}_{\text {III }}$ did not change with $\mathrm{CO}_{\text {down }}$ (Table 2). Concerns about which hemodynamic parameter, $\mathrm{CO}$ or pulmonary artery pressure, affect $S \mathrm{n}_{\text {III }}$ the most are raised. Statistical analysis revealed that $\mathrm{CO}$ was the dominating factor even during hypoxaemia when $\mathrm{CO}$ and MPAP changed in opposite directions.

4.2 The elimination of $\mathrm{CO}_{2}$

$\mathrm{VTCO}_{2, \text { br }}$ is the primary VCap variable because it reflects the $\mathrm{CO}_{2}$ kinetics of the entire body; therefore it changes 


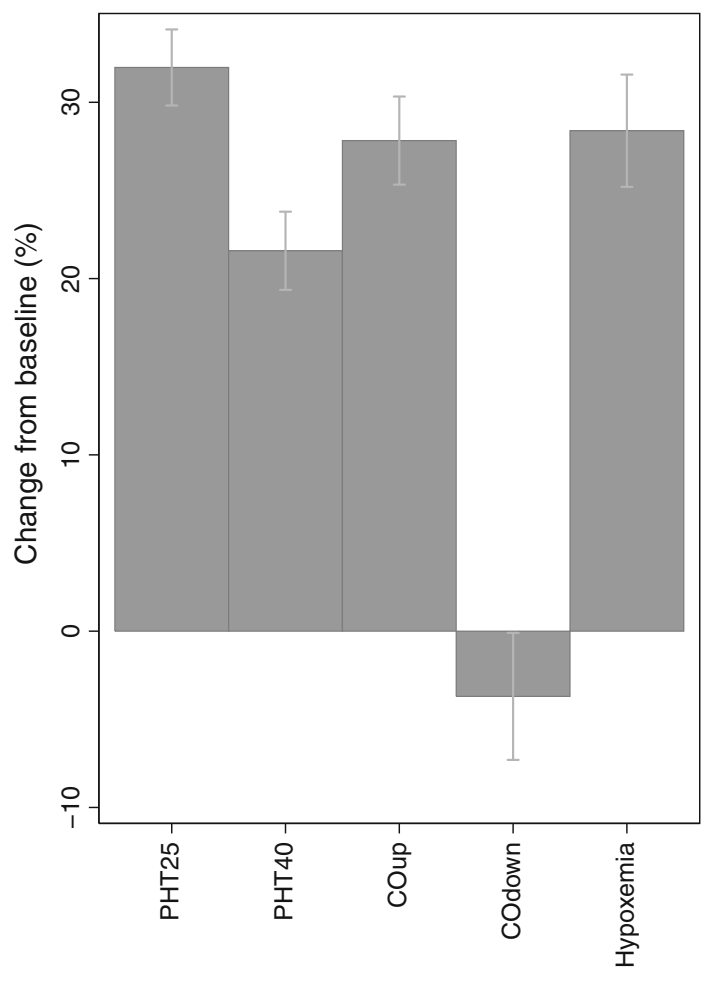

Difference (\%) $\longmapsto$ se (\%)

Fig. 2 Change in the normalized slope III (SnIII) from baseline to measurement conditions. Percent change of SnIII from respective baseline value during the 5 protocol conditions. $\mathrm{PHT}_{25}$, pulmonary hypertension of $25 \mathrm{mmHg}$; $\mathrm{PHT}_{40}$, pulmonary hypertension of $40 \mathrm{mmHg} ; \mathrm{CO}_{\text {up }}$, increase in cardiac output by $50 \% ; \mathrm{CO}_{\text {down }}$, decrease in cardiac output by $40 \%$; Hypoxemia, delivery of hypoxic gas mixture at $\mathrm{FiO}_{2}$ of 0.07 to induce a combination of PHT and $\mathrm{CO}_{\text {down }}$. Difference, change in percent between baseline and measurement; se, standard error

with changing metabolism, pulmonary perfusion and alveolar ventilation [34]. The design of our protocol allowed us to determine the role that pulmonary blood flow and pressure have on this important variable. It is well known that $\mathrm{VTCO}_{2 \text {,br }}$ decreases under conditions of low pulmonary blood flow as during severe hypovolemia, pulmonary embolism or during cardio-pulmonary resuscitations $[9,35]$. Our results fit with these findings although the changes we observed in $\mathrm{VTCO}_{2, \text { br }}$ were lower.

In our protocol, $\mathrm{VTCO}_{2, \text { br }}$ increased with increasing $\mathrm{CO}$ but decreased when $\mathrm{CO}$ went down indicating that this variable is highly dependent on the amount of pulmonary flow. Our statistical mixed random effects model confirmed these findings. However, major changes in $\mathrm{VTCO}_{2, \text { br }}$ where observed only with decreasing $\mathrm{CO}$. The reduction in preload due to drug induced vasodilation during $\mathrm{CO}_{\text {down }}$ created a relative hypovolemia, which has known deleterious effect on the lungs' elimination of $\mathrm{CO}_{2}$. The minimal increases in $\mathrm{VTCO}_{2, \text { br }}$ at high $\mathrm{CO}$ levels can be explained

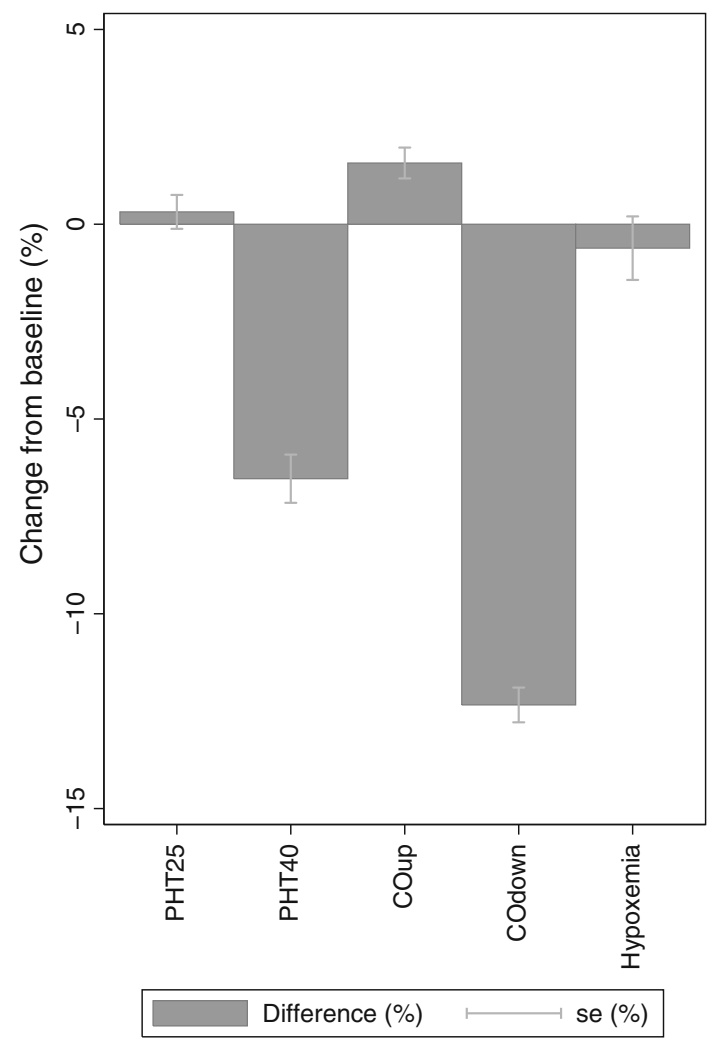

Fig. 3 Changes in the expired volume of $\mathrm{CO}_{2}\left(\mathrm{VTCO}_{2, \mathrm{br}}\right)$ from baseline to measurement conditions. Percent change of $\mathrm{VTCO}_{2, \mathrm{br}}$ from respective baseline value during the 5 protocol steps. $\mathrm{PHT}_{25}$, pulmonary hypertension of $25 \mathrm{mmHg}$; $\mathrm{PHT}_{40}$, pulmonary hypertension of $40 \mathrm{mmHg} ; \mathrm{CO}_{\text {up }}$, increase in cardiac output by $50 \% ; \mathrm{CO}_{\text {down }}$, decrease in cardiac output by $40 \%$; Hypoxemia, delivery of hypoxic gas mixture at $\mathrm{FiO}_{2}$ of 0.07 to induce a combination of PHT and $\mathrm{CO}_{\text {down }}$. Difference, change in percent between baseline and measurement; se, standard error

by the fact that the lungs had already been well perfused at baseline. Therefore, increases in $\mathrm{CO}$ by more than $50 \%$ were unable to increase $\mathrm{CO}_{2}$ elimination any more without increasing alveolar ventilation. Thus, $\mathrm{CO}$ reached a point at which $\mathrm{CO}_{2}$ elimination became ventilation-dependent.

\subsection{The effects on dead space}

Bohr's dead space and it components, the airway and alveolar dead space, were not altered during the protocol steps. These findings were partially expected because ventilation was fixed along the study and because dead space is representing the portion of ventilation that does not participate in gas exchange [2, 19]. However, we expected an increase in alveolar dead space at $\mathrm{CO}_{\text {down }}$ due to a shift of the lung's tissue towards West's zone I condition characterized by a local deficit in lung perfusion. We have recently described how $\mathrm{VD}_{\text {alv }}$ depends on pulmonary perfusion using again the above-mentioned model of weaning 
from cardio-pulmonary bypass $[9,36]$. A possible explanation for the lack of change in alveolar dead space might be the use of nitroglycerine, which was used to decrease $\mathrm{CO}$. Nitroglycerine acts as a vasodilator after conversion to nitric oxide within the body. NO improves gas exchange by redirecting blood flow away from shunting lung units to those with a more ideal V/Q ratio. This reduces dead space without affecting pulmonary vascular resistance [37, 38]. For this reason the expected increase in $\mathrm{VD}_{\text {alv }}$ during $\mathrm{CO}_{\text {down }}$ in our study was probably masked by the effect of the nitroglycerine administered.

Enghoff's global index of the inefficiency of gas exchange, erroneously considered as "dead space", was mainly affected by $\mathrm{CO}_{\text {down }}$ conditions $[20,21]$. In theory the difference between Bohr's and Enghoff's equations is the influence of venous admixture [21]. Therefore, Enghoff's index is more an indicator of global ventilationperfusion inequality than a marker of dead space. However, in our study the increase in Enghoff's index at $\mathrm{CO}_{\text {down }}$ cannot be explained solely by the manipulation of the individual hemodynamic parameters. The administration of nitroglycerine and the alterations of lung perfusion in relation to the constant ventilation might have caused shifts in the V/Q matching that resulted in an increase in Enghoff's index.

\subsection{Pitfalls}

It was impossible in our model to induce isolated pure changes in $\mathrm{CO}$ or pulmonary pressure without affecting each other or altering to some extent also the other hemodynamic variables. For example, $\mathrm{CO}_{\text {up }}$ and $\mathrm{CO}_{\text {down }}$ increased and decreased mean pulmonary artery pressure and venous admixture, respectively. Therefore, the effect of changes in CO on VCap could be affected (and explained) also by slight changes in other hemodynamic variables. To account for the physiologic influence of the other haemodynamic factors a mixed model was used to detect the major cause for VCap changes. The model revealed that variations in $\mathrm{CO}$ were responsible for most of the changes seen in the VCap variables. However, the other measured hemodynamic variables influenced the VCap variables, too, but to a lesser extent, leaving clinicians with the certainty that all factors which influence pulmonary blood flow will also have some impact on VCap, especially on variables primarily related to the shape of the capnogram.

The use of nitroglycerine to induce a fall in $\mathrm{CO}$ might have influenced our dead space measurements. Therefore, to avoid the direct effect of nitric oxide on the pulmonary vasculature, in future studies other interventions to reduce $\mathrm{CO}$ such as inflation of a cava balloon should be considered.

\section{Conclusions}

Changes in pulmonary artery blood flow and pressure greatly modified the shape of the volumetric capnogram without influencing dead space variables. Increasing pulmonary artery pressures and COs lead to parallel increases in the slopes of phase III. Lower COs resulted in lower amount of $\mathrm{CO}_{2}$ eliminated during one breathing cycle. This novel information might be useful to better interpret VCap derived-variables in mechanically ventilated patients.

Acknowledgments This study was supported by Axon Lab (Instrumentation Laboratory, Axon Lab, Switzerland) and funded by a grant from the Forschungskredit of the University of Zürich, awarded to M. Mosing.

Conflict of interest The authors declare that they have no conflict of interest.

Ethical Standards This study was approved by the Cantonal Veterinary Office of Zürich (176/2011).

\section{References}

1. Aitken RS, Clark-Kennedy AE. On the fluctuation in the composition of the alveolar air during the respiratory cycle in muscular exercise. J Physiol. 1928;65:389-411.

2. Fletcher R, Jonson B, Cumming G, Brew J. The concept of deadspace with special reference to the single breath test for carbon dioxide. Br J Anaesth. 1981;53:77-88.

3. Breen PH, Isserles SA, Harrison BA, Roizen MF. Simple computer measurement of pulmonary $\mathrm{VCO} 2$ per breath. J Appl Physiol. 1992;72:2029-35.

4. Breen PH, Mazumdar B, Skinner SC. Comparison of end-tidal $\mathrm{PCO} 2$ and average alveolar expired $\mathrm{PCO} 2$ during positive endexpiratory pressure. Anesth Analg. 1996;82:368-73.

5. Fletcher R, Jonson B. Deadspace and the single breath test for carbon dioxide during anaesthesia and artificial ventilation. Effects of tidal volume and frequency of respiration. Br J Anaesth. 1984;56:109-19.

6. Maisch S, Reissmann H, Fuellekrug B, Weismann D, Rutkowski T, Tusman G, Bohm SH. Compliance and dead space fraction indicate an optimal level of positive end-expiratory pressure after recruitment in anesthetized patients. Anesth Analg. 2008;106: 175-81. doi:10.1213/01.ane.0000287684.74505.49.

7. Taskar V, John J, Larsson A, Wetterberg T, Jonson B. Dynamics of carbon dioxide elimination following ventilator resetting. Chest. 1995;108:196-202.

8. Kallet RH, Daniel BM, Garcia O, Matthay MA. Accuracy of physiologic dead space measurements in patients with acute respiratory distress syndrome using volumetric capnography: comparison with the metabolic monitor method. Respir Care. 2005;50:462-7.

9. Tusman G, Areta M, Climente C, Plit R, Suarez-Sipmann F, Rodriguez-Nieto MJ, Peces-Barba G, Turchetto E, Bohm SH. Effect of pulmonary perfusion on the slopes of single-breath test of CO2. J Appl Physiol. 2005;99:650-5.

10. Burki NK. The dead space to tidal volume ratio in the diagnosis of pulmonary embolism. Am Rev Respir Dis. 1986;133:679-85.

11. Tusman G, Bohm SH, Suarez-Sipmann F, Turchetto E. Alveolar recruitment improves ventilatory efficiency of the lungs during 
anesthesia. Can J Anaesth. 2004;51:723-7. doi:10.1007/BF0301 8433.

12. Bohm SH, Maisch S, von Sandersleben A, Thamm O, Passoni I, Martinez Arca J, Tusman G. The effects of lung recruitment on the Phase III slope of volumetric capnography in morbidly obese patients. Anesth Analg. 2009;109:151-9. doi:10.1213/ane. 0b013e31819bcbb5.

13. Mosing M, Iff I, Hirt R, Moens Y, Tusman G. Evaluation of variables to describe the shape of volumetric capnography curves during bronchoconstriction in dogs. Res Vet Sci. 2012;93: 386-92. doi:10.1016/j.rvsc.2011.05.014.

14. Crawford AB, Makowska M, Paiva M, Engel LA. Convectionand diffusion-dependent ventilation maldistribution in normal subjects. J Appl Physiol. 1985;59:838-46.

15. Horsfield K, Cumming G. Functional consequences of airway morphology. J Appl Physiol. 1968;24:384-90.

16. Verbanck S, Paiva M. Model simulations of gas mixing and ventilation distribution in the human lung. J Appl Physiol. 1990;69:2269-79.

17. Tusman G, Suarez-Sipmann F, Bohm SH, Borges JB, Hedenstierna G. Capnography reflects ventilation/perfusion distribution in a model of acute lung injury. Acta Anaesthesiol Scand. 2011;55:597-606. doi:10.1111/j.1399-6576.2011.02404.x.

18. Tusman G, Scandurra A, Bohm SH, Suarez-Sipmann F, Clara F. Model fitting of volumetric capnograms improves calculations of airway dead space and slope of phase III. J Clin Monit Comput. 2009;23:197-206. doi:10.1007/s10877-009-9182-z.

19. Bohr C. Über die Lungenathmung. Centralblatt für Physiologie. 1887;1(14):236-68.

20. Enghoff H. Volumen inefficax. Bemerkungen zur Frage des schädlichen Raumes. Uppsala Lak Forhandl. 1938;44:191-218.

21. Tusman G, Sipmann FS, Bohm SH. Rationale of dead space measurement by volumetric capnography. Anesth Analg. 2012; 114:866-74. doi:10.1213/ANE.0b013e318247f6cc.

22. Berggren SM. The oxygen deficit of arterial blood caused by nonventilated parts of the lung. Acta Physiol Scand. 1942;4:4-9.

23. Stromberg NO, Gustafsson PM. Ventilation inhomogeneity assessed by nitrogen washout and ventilation-perfusion mismatch by capnography in stable and induced airway obstruction. Pediatr Pulmonol. 2000;29:94-102. doi:10.1002/(SICI)1099-0496(200 002)29:2<94.

24. Downie SR, Salome CM, Verbanck S, Thompson B, Berend N, King GG. Ventilation heterogeneity is a major determinant of airway hyperresponsiveness in asthma, independent of airway inflammation. Thorax. 2007;62:684-9. doi:10.1136/thx.2006. 069682.

25. Tusman G, Gogniat E, Bohm SH, Scandurra A, Suarez-Sipmann F, Torroba A, Casella F, Giannasi S, Roman ES. Reference values for volumetric capnography-derived non-invasive parameters in healthy individuals. J Clin Monit Comput. 2013;27: 281-8. doi:10.1007/s10877-013-9433-x.

26. Verschuren F, Liistro G, Coffeng R, Thys F, Roeseler J, Zech F, Reynaert M. Volumetric capnography as a screening test for pulmonary embolism in the emergency department. Chest. 2004; $125: 841-50$

27. Kline JA, Israel EG, Michelson EA, O'Neil BJ, Plewa MC, Portelli DC. Diagnostic accuracy of a bedside D-dimer assay and alveolar dead-space measurement for rapid exclusion of pulmonary embolism: a multicenter study. JAMA. 2001;285:761-8.

28. Glenny RW, Robertson HT. Fractal properties of pulmonary blood flow: characterization of spatial heterogeneity. J Appl Physiol. 1990;69:532-45.

29. Glenny RW, Lamm WJ, Albert RK, Robertson HT. Gravity is a minor determinant of pulmonary blood flow distribution. J Appl Physiol. 1991;71:620-9.

30. Hakim TS, Lisbona R, Dean GW. Gravity-independent inequality in pulmonary blood flow in humans. J Appl Physiol. 1987;63: 1114-21.

31. Hakim TS, Lisbona R, Dean GW. Effect of cardiac output on gravity-dependent and nondependent inequality in pulmonary blood flow. J Appl Physiol. 1989;66:1570-8.

32. Presson RG Jr, Baumgartner WA Jr, Peterson AJ, Glenny RW, Wagner WW Jr. Pulmonary capillaries are recruited during pulsatile flow. J Appl Physiol. 2002;92:1183-90. doi:10.1152/jappl physiol.00845.2001.

33. Wagner WW Jr, Latham LP. Pulmonary capillary recruitment during airway hypoxia in the dog. J Appl Physiol. 1975;39:900-5.

34. Tusman G, Bohm SH, Suarez-Sipmann F, Scandurra A, Hedenstierna $\mathrm{G}$. Lung recruitment and positive end-expiratory pressure have different effects on $\mathrm{CO} 2$ elimination in healthy and sick lungs. Anesth Analg. 2010;111:968-77. doi:10.1213/ANE.0b013e 3181f0c2da.

35. Fletcher R. Deadspace, invasive and non-invasive. Br J Anaesth. 1985;57:245-9.

36. Tusman G, Suarez-Sipmann F, Paez G, Alvarez J, Bohm SH. States of low pulmonary blood flow can be detected non-invasively at the bedside measuring alveolar dead space. J Clin Monit Comput. 2012;26:183-90. doi:10.1007/s10877-012-9358-9.

37. Putensen C, Rasanen J, Downs JB. Effect of endogenous and inhaled nitric oxide on the ventilation-perfusion relationships in oleic-acid lung injury. Am J Respir Crit Care Med. 1994;150: 330-6. doi:10.1164/ajrccm.150.2.8049811.

38. Skimming JW, Banner MJ, Spalding HK, Jaeger MJ, Burchfield DJ, Davenport PW. Nitric oxide inhalation increases alveolar gas exchange by decreasing deadspace volume. Crit Care Med. 2001;29:1195-200. 